\title{
A histo-topographic map of the Dutch university studies
}

Citation for published version (APA):

Borghans, L. (1992). A histo-topographic map of the Dutch university studies. Researchcentrum voor Onderwijs en Arbeidsmarkt, Faculteit der Economische Wetenschappen. ROA Working Papers No. 5E https://doi.org/10.26481/umarow.199205E

Document status and date:

Published: 01/01/1992

DOI:

10.26481/umarow.199205E

Document Version:

Publisher's PDF, also known as Version of record

\section{Please check the document version of this publication:}

- A submitted manuscript is the version of the article upon submission and before peer-review. There can be important differences between the submitted version and the official published version of record.

People interested in the research are advised to contact the author for the final version of the publication, or visit the DOI to the publisher's website.

- The final author version and the galley proof are versions of the publication after peer review.

- The final published version features the final layout of the paper including the volume, issue and page numbers.

Link to publication

\footnotetext{
General rights rights.

- You may freely distribute the URL identifying the publication in the public portal. please follow below link for the End User Agreement:

www.umlib.nl/taverne-license

Take down policy

If you believe that this document breaches copyright please contact us at:

repository@maastrichtuniversity.nl

providing details and we will investigate your claim.
}

Copyright and moral rights for the publications made accessible in the public portal are retained by the authors and/or other copyright owners and it is a condition of accessing publications that users recognise and abide by the legal requirements associated with these

- Users may download and print one copy of any publication from the public portal for the purpose of private study or research.

- You may not further distribute the material or use it for any profit-making activity or commercial gain

If the publication is distributed under the terms of Article $25 \mathrm{fa}$ of the Dutch Copyright Act, indicated by the "Taverne" license above, 
A HISTO-TOPOGRAPHIC MAP OF THE DUTCH UNIVERSITY STUDIES

ROA-W-1992/5E

Lex Borghans

Faculty of Economics and Business Administration

Rijksuniversiteit Limburg

Maastricht, June 1992 


\section{CIP-GEGEVENS KONINKLIJKE BIBLIOTHEEK, DEN HAAG}

Borghans, Lex

A histo-topographic map of the Dutch university studies / Lex Borghans. - Maastricht: Research Centre for Education and Labour Market, Faculty of Economics and Business Administration, Rijksuniversiteit Limburg. -(Working paper/ Research Centre for Education and the Labour Market, ISSN 0922-4645; 1992/5E)

Met lit. opg.

ISBN 90-5321-086-5 in ringband

Trefw.: wetenschappelijk onderwijs; Nederland. 
CONTENTS

Page

$\begin{array}{ll}\text { ABSTRACT } & \text { i }\end{array}$

1. INTRODUCTION

2. SPECIALISATION AND FLEXIBILITY 2

3. MEASUREMENT 4

4. THE DATA 11

5. SPECIALISATION AND LABOUR MARKET BEHAVIOUR 22

6. CONCLUDING REMARKS 27

$\begin{array}{lr}\text { REFERENCES } & 28\end{array}$

$\begin{array}{lr}\text { APPENDIX } & 29\end{array}$ 


\section{ABSTRACT}

In this paper a measure is introduced to map the educational structure of the labour market. It measures both the similarity between studies and the degree of specialisation of every study. The measure is based on the distribution of workers over the different occupations. A correction is made for similarities between occupations. Based on this measure the educational structure of the Dutch university studies is mapped for 1947-1985. Finally, it is shown that due to high average levels of unemployment, general studies face more labour market uncertainty than specialised studies. 


\section{INTRODUCTION}

The structure of the market for educated labour is complex. On the one hand educated labour is not a homogenous good, but on the other hand people with different educational backgrounds often have similar occupations. Furthermore, this relation is subject to changes in time. Studies which once gave access to certain occupations get replaced by others. For students starting with their education it is important to have some insight in the relation between education and labour market. Their educational choice will to some extent determine their future possibilities at the labour market.

The aim of this paper is to describe the structure of the Dutch university studies through time. In this respect two dimensions are important. Firstly, the allocation of a certain study determines what occupations it gives access to, and which neighbourhood studies give access to the same occupations. Secondly, the extent of a study indicates its degree of specialisation. While specialised studies will fit closer to a specific occupation, general studies will give the student more flexibility at the labour market.

In the literature about the structure of the Dutch labour market, the flexibility of a study and its location are mostly treated separately. Teulings (1988) and De Grip, Groot, and Heijke (1991) classify occupations in clusters according to educational characteristics of the workers. The disadvantage of clustering is that $a$, to some extent arbitrary, delineation has to be made, masking the gradual changes between occupations or between educations. In this paper the connections between educations is mapped without clustering them, and attention is paid to the dynamics of these relations. Furthermore, the method of clustering is not symmetric with respect to education and occupation. A clustering of occupations will not automatically provide a related clustering of educations. Although this paper focuses on the structure of the education, the method provides similar results for occupations.

The flexibility of university studies is for example studied in De Grip and Heijke (1988, 1989). Following Warnken (1986) they use the Gini-Hirschman index as a measure of flexibility. This measure does, however, not take into account the structure of the occupations, treating all occupations as completely different. In this paper an adjusted version of the Gini-Hirschman index will be used, taking explicitly into account the occupational structure. 


\section{SPECIALISATION AND FLEXIBILITY}

It is in general not the case that for every occupation a specific education exists. A particular study might lead to rather different occupations while a particular occupation might be practised by people with a different educational background.

From one point of view this situation is inefficient, since job-specific education will make students better equipped for their specific tasks. On the other hand, however, such a jobspecific education will make the match between education and labour market very inflexible. In case of uncertainty about the future developments of the demand for certain types of labour it is profitable not to specialise completely, but to keep open a group of future occupation. Depending on the situation it is optimal to create a compromise between complete specialisation and complete flexibility. This compromise can be found both at the individual and at the aggregated level.

For an individual student, both specialisation and generalisation lead to certain costs. Specialisation increases the risk of a mismatch, i.e. the risk that at the moment the student enters the labour market the demand for this type of educated labour is low. Generalisation, on the other hand, diminishes the productivity of the worker, and assuming that wages equal the productivity, thereby the wage. Although a general education gives access to a range of occupations the student will get only one occupation, making the human capital related to the other occupations superfluous. The individual optimum is at the point where the costs of specialisation equal the costs of generalisation. As long as generalisation is possible without large investments it is worthwhile. As long as specialisation is possible without large increases in the risk of getting an appropriate job it is worthwhile.

The individual optimal degree of specialisation therefore depends on the predictability of the future labour market situation, and on the specificity of the requirements of the occupation.

On aggregated level there also is an optimal compromise between specialism and flexibility. Firstly, some occupations require highly specialised professionals, or a high degree of certainty regarding the labour market makes specialisation profitable. Secondly, in order to make it possible to respond accurately to changes at the labour market, it is not necessarily that everybody is generally educated. The presence of a group of generalists makes it possible for others to specialise. In case of an unexpected shift at the labour market the generalists will shift from one occupation to another, thereby smoothing the shock.

The specialistic studies are suitable for students with a large preference for a specific occupation, i.e. with relatively low individual uncertainty, while the general studies are suitable for students who doubt about their favourite job, i.e. with a relative high individual uncertainty.

Under the assumption that wages reflect productivity, the specialists earn more than the generalists, but this difference is individually compensated by the possibility to postpone the 
decision which occupation to study for. Dothan and Williams (1981) call this the option value of education. In this framework it is expected that given the occupation, people with a specialistic study earn more, but in general both earnings and enrolment will fluctuate more than in general studies.

This argument is, however, based on the assumption that productivity is reflected in the wages. The existence of rationing might disturb these relations. Assume for example the wages to be fixed. In that case employers will first employ the most productive workers, which will be mostly the specialists, and only in case of a shortage generalists are hired. The generalists therefore bear a large part of the risk of unemployment, making general studies less attractive in case of high unemployment. Specialists therefore have a high probability to get a job, but also this probability and thereby the enrolment fluctuates less than in case of general studies. 


\section{MEASUREMENT}

The aim of this paper is to measure the similarities between university studies and the degree of specialisation of these studies. In literature most examples of the measurement of similarity can be found in cluster analysis (for example Teulings (1988) and De Grip, Groot, and Heijke (1991)). The aim of cluster analysis is, however, to put studies (or mostly occupations) together in some classes. These enforced barriers conceal the fact that mostly the transition from one cluster to another is very fluent. In this study, therefore, only the similarities are measured, without clustering. A measure is used which can be connected with the measure of the degree of specialisation straightforwardly.

In the literature about the flexibility of studies (e.g. Sheldon (1985), Warnken (1986), and De Grip and Heijke (1989)), the Gini-Hirschman index is used to measure the degree of specialisation. The Gini-Hirschman index for study $i$ is defined as: ${ }^{1}$

(1) $G H_{i}^{\text {educ }}=\sum_{j}\left(\frac{p_{i j}}{p_{. j}}\right)^{2}$

in which $p_{i j}$ is the fraction of workers with education $i$ in occupation $j$ and $p_{. j}$ denotes the sum over $i$ of $p_{i j}: p_{j}=\sum_{i} p_{i j}$. If every student in $i$ gets occupation $j$ the index will be 1 . If the students are spread equally over the occupations and there are many occupations the index will become almost 0 .

Formula (1) can be rewritten as:

(2) $G H_{i}^{e d u c}=\sum_{j} \sum_{i j}\left(\frac{p_{i j}}{p_{, j}}\right)\left(\frac{p_{i j j}}{p_{, j j}}\right) s(j, j j)$

in which $\left\{\begin{array}{lll}s(j, j j)=1 & \text { if } \quad j=j j \\ s(j, j j)=0 & \text { if } \quad j \neq j j\end{array}\right.$

The Gini-Hirschman index in formula (2) can be interpreted as follows. Take a random person with education $i$. Give him a new occupation also at random corresponding to the actual distribution of workers with education $i$ over the occupations. The Gini-Hirschman is then the expected similarity between the old and the new job, with the similarity-index $s$ only equal to 1 if the old job equals the new job. Of course, the expected similarity will be high if many workers with the same education work in the same occupation.

The Gini-Hirschman index for an occupation can be defined similarly:

(3) $G H_{j}^{o c c}=\sum_{i}\left(\frac{p_{i j}}{p_{i .}}\right)^{2}$

1. In the studies mentioned a monotone transformation of this index is used. 
A disadvantage of the Gini-Hirschman index is the fact that it is very sensitive for the classification of occupations which is used. As shown in the interpretation, the Gini-Hirschman index assumes all occupations within a group to be totally similar, while every occupation outside the group has absolutely no similarity. As a result of this, educations for which the relevant occupations are classified very specific will get a low Gini-Hirschman index. Furthermore, occupations which are completely different are treated equally to occupations which are rather similar.

To overcome these problems with the measurement of specialisation it is useful to adjust the Gini-Hirschman index with a real similarity function. For this purpose a similarity index used in cluster analysis is used, called the cosine criterion (see Lorr, 1983):

(4) $s_{1}^{o c c}(j, j j)=\frac{\sum_{i}\left(\frac{p_{i j}}{p_{i .}}\right)\left(\frac{p_{i j j}}{p_{i .}}\right)}{\sqrt{\sum_{i}\left(\frac{p_{i j}}{p_{i .}}\right)^{2} \cdot \sum_{i}\left(\frac{p_{i j j}}{p_{i .}}\right)^{2}}}$

This similarity measure equals the cosine of the angle between the vectors of distribution of the workers in a specific occupation over their background studies $\left(p_{1 j}, p_{2 j}, \ldots, p_{I j}\right)$. If the distribution is equal for two occupations $j$ and $j j$, the angle equals 0 , and therefore the similarity equals 1 $(=\cos (0))$. If for all educations which appear in occupation $j$ there is no worker with this education in occupation $j j$ and v.v., the distribution vectors form a right angle, so the similarity equals $0(=\cos (90))$.

Defining

(5) $G H_{j, j j}^{o c c}=\sum_{i}\left(\frac{p_{i j}}{p_{i .}}\right)\left(\frac{p_{i j j}}{p_{i .}}\right)$

which can be compared to the covariance belonging to the 'variance' $G H_{j}^{o c c}$, this equation can be rewritten as:

(6) $s_{1}^{o c c}(j, j j)=\frac{G H_{j, j}^{o c c}}{\sqrt{G H_{j}^{o c c} G H_{j j}^{o c c}}}$

In a similar way the similarity of educations might be measured. These similarity measures make it possible to adjust the Gini-Hirschman index in a second stage of calculation:

(7) $A G H_{i}^{\text {educ }}=\sum_{j} \sum_{j j}\left(\frac{p_{i j}}{p_{. j}}\right)\left(\frac{p_{i j j}}{p_{, j j}}\right)^{o c c}(j, j j)$

Connected to this Adjusted Gini-Hirschman index, in this second stage, an adjusted similarity measure can be calculated, based on the $A G H$, and therefore on the first stage similarities of the occupations in case of education, and the first stage similarities of studies in the case of occupations. 
(8) $s_{2}^{\text {educ }}(i, i i)=\frac{A G H_{i, i i}^{\text {educ }}}{\sqrt{A G H_{i}^{\text {educ }} A G H_{i i}^{\text {educ }}}}$

Figure 1 illustrates the two stages of calculation of these adjusted indexes.

Figure 1: The two stages of calculation of the Adjusted Gini-Hirschman and the similarity index

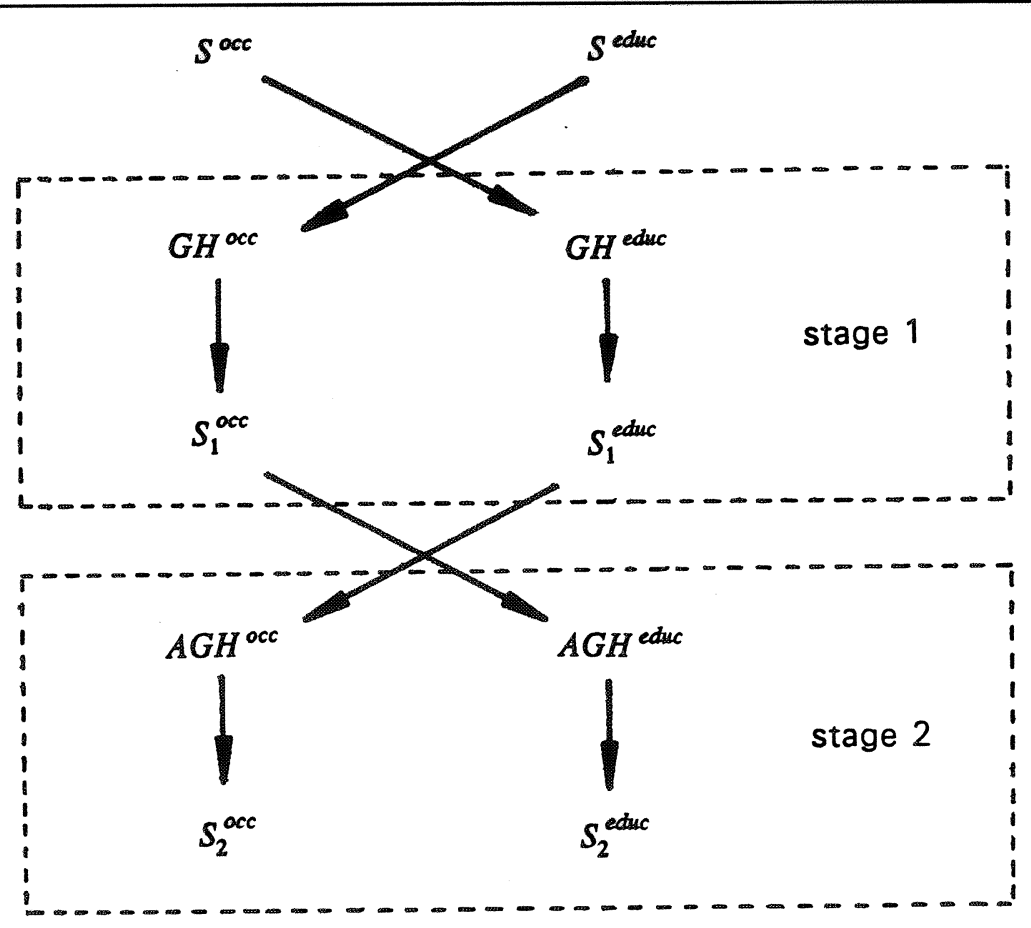

In the appendix the listing of a computer-program is provided which calculates the two stages of the Gini-Hirschman and the similarity index. The following two examples will show some properties of this procedure.

\section{Example 1}

Table 1. Matrix education $\times$ occupation

$\begin{array}{rrrr}1 & 10 & 5 & 0 \\ 2 & 0 & 0 & 10\end{array}$


Table 2. Gini-Hirschman index for education

\begin{tabular}{ll}
\hline education i & $G H_{i}^{\text {educ }}$ \\
\hline 1 & 0.56 \\
2 & 1.00 \\
\hline
\end{tabular}

Table 3. Gini-Hirschman index for occupation

\begin{tabular}{ll}
\hline occupation j & $G H_{j}^{\text {occ }}$ \\
\hline & \\
1 & 1.00 \\
3 & 1.00 \\
\hline
\end{tabular}

Table 4. First stage similarities, education

\begin{tabular}{lcc}
\hline educ ileduc ii & 1 & 2 \\
\hline & & \\
2 & 1.00 & 0.00 \\
2 & 0.00 & 1.00 \\
\hline
\end{tabular}

Table 5. First stage similarities, occupation

\begin{tabular}{lrrr}
\hline occ jlocc jj & 1 & 2 & 3 \\
\hline & & & \\
1 & 1.00 & 1.00 & 0.00 \\
2 & 1.00 & 1.00 & 0.00 \\
3 & 0.00 & 0.00 & 1.00 \\
\hline
\end{tabular}

Table 6. Adjusted Gini-Hirschman index for education

\begin{tabular}{ll}
\hline educ i & $A G H_{i}^{\text {educ }}$ \\
\hline & \\
2 & 1.00 \\
\hline
\end{tabular}


Table 7. Adjusted Gini-Hirschman index for occupation

\begin{tabular}{ll} 
occ j & $A G H_{j}^{\text {occ }}$ \\
\hline 1 & 1.00 \\
2 & 1.00 \\
3 & 1.00 \\
\hline
\end{tabular}

Table 8. Second stage similarities, education

\begin{tabular}{lrr} 
educ ileduc ii & 1 & 2 \\
\hline 1 & 1.00 & 0.00 \\
2 & 0.00 & 1.00
\end{tabular}

Table 9. Second stage similarities, occupation

\begin{tabular}{lrrr} 
occ jlocc jj & 1 & 2 & 3 \\
\hline 1 & & & \\
2 & 1.00 & 1.00 & 0.00 \\
3 & 1.00 & 1.00 & 0.00 \\
& 0.00 & 0.00 & 1.00
\end{tabular}

In the first example students with education 1 get occupation 1 and 2, while students with education 2 get occupation 3 (table 1). The Gini-Hirschman index for education 1 is not equal to 1 since the students have a flexibility between occupation 1 and 2 (table 2). Occupation 1 and 2 have, however, a completely similar educational structure. Therefore the similarity between occupation 1 and occupation 2 equals 1 (table 5 ). Due to this similarity the Adjusted GiniHirschman index for study 1 also gets 1 . The second stage similarities equal the first stage similarities.

\section{Example 2}

Table 10. Matrix education x occupation

$\begin{array}{rrr}1 & 10 & 10 \\ 2 & 10 & 0 \\ 3 & 0 & 10\end{array}$


$-9-$

Table 11. Gini-Hirschman index for education

\begin{tabular}{ll} 
education i & $\boldsymbol{G H}_{\boldsymbol{i}}^{\text {educ }}$ \\
\hline 1 & \\
2 & 0.50 \\
3 & 1.00 \\
& 1.00
\end{tabular}

Table 12. Gini-Hirschman index for occupation

\begin{tabular}{ll} 
occupation j & $\boldsymbol{G} \boldsymbol{H}_{\boldsymbol{j}}^{\text {occ }}$ \\
\hline 1 & \\
2 & 0.50 \\
& 0.50
\end{tabular}

Table 13. First stage similarities, education

\begin{tabular}{lrrr} 
educ ileduc ii & 1 & 2 & 3 \\
\hline & & & \\
2 & 1.00 & 0.71 & 0.71 \\
3 & 0.71 & 1.00 & 0.00 \\
& 0.71 & 0.00 & 1.00 \\
\hline
\end{tabular}

Table 14. First stage similarities, occupation

\begin{tabular}{lcc}
\hline occ jlocc jj & \multicolumn{1}{c}{2} \\
\hline & 1 & \\
1 & 1.00 & 0.50 \\
2 & 0.50 & 1.00 \\
\hline
\end{tabular}

Table 15. Adjusted Gini-Hirschman index for education

\begin{tabular}{ll}
\hline education i & $A G H_{i}^{\text {educ }}$ \\
\hline & \\
\hline & 0.75 \\
3 & 1.00 \\
\hline
\end{tabular}


Table 16. Adjusted Gini-Hirschman index for occupation

\begin{tabular}{ll} 
occupation j & $A G H_{j}{ }^{\circ}$ \\
\hline 1 & \\
2 & 0.85 \\
& 0.85
\end{tabular}

Table 17. Second stage similarities, education

\begin{tabular}{lccc} 
educ ileduc ii & 1 & 2 & 3 \\
\hline 1 & 1.00 & 0.87 & 0.87 \\
2 & 0.87 & 1.00 & 0.50 \\
3 & 0.87 & 0.50 & 1.00 \\
\hline
\end{tabular}

Table 18. Second stage similarities, occupation

\begin{tabular}{lrr} 
occ jlocc jj & 1 & 2 \\
\hline 1 & 1.00 & 0.71 \\
2 & 0.71 & 1.00
\end{tabular}

In the second example education 1 gives access to both occupation 1 and 2, while students of 2 only get job 1 and students of 3 only job 2. Education 2 and 3 therefore are specialistic studies in the same labour market segment as the more general study 1 . The Gini-Hirschman index for study 1 equals 0.50 , while the Gini-Hirschman index of study 2 and 3 equals 1 . The similarity between education 1 and 2 and between 1 and 3 is 0.71 in the first stage, while the similarity between 2 and 3 equals 0 . The fact that students with study 1 get both jobs in occupation 1 and 2 makes the similarity between occupation 1 and 2 non-zero. In the second stage this similarity between the occupations increases the Adjusted Gini-Hirschman index of study 1 , and the similarities between study 2 and 3 become non-zero. 


\section{THE DATA}

The method for analysing the structure of occupations and educations has been used for the Dutch university labour market from 1947 till 1985. The data-matrixes occupation $x$ education have been taken from the Dutch censuses 1947, 1960, and 1971 and the Dutch Labour Market Censuses (AKT) of 1979, 1981, 1983, and 1985. Educations have been clustered into 12 groups according to Dekker et al (1990), to make inter-temporal comparison possible. It is of course also possible to carry out the analysis at a lower level of aggregation, producing in this way extra detailed information. For expository goals, however, this procedure produces too much information. These 12 educational groups are provided in table 19, together with the abbreviation used in this paper and the number of people working with this education in 1979 . For occupations the clustering used in the original source have been used. These clusterings are, however, not comparable through time, which sometimes leads to enormous shift in the observed structure. The most striking example concerns physicians and pharmacists, which are sometimes in the same occupational group and sometimes not, making the similarity between pharmacology and medicines vary from 0.06 in 1947 to 1.00 in 1979. Another problem concerns the teachers, which are all classified in one occupational group, regardless of the subject they teach. This creates a large similarity between university studies with many people in teaching occupations as for example languages and mathematics. To avoid this problem the teaching profession has been split up into 12 different groups related to the educational background of the teacher. Furthermore, the large number of occupations makes it impossible to present the results with respect to occupations.

Table 19. List of university studies, with their abbreviations and the amount of people working in 1979 with this study

\begin{tabular}{rlrr}
\hline & & & \\
& university study & abbreviation & \# in 1979 \\
& & & \\
1 & Languages & LAN & 11.595 \\
2 & Theology & THE & 5.165 \\
3 & Agricultural sciences & AGR & 3.193 \\
4 & Mathematics and natural sciences & MAT & 20.291 \\
5 & Technology & TEC & 27.441 \\
6 & Medicine & MED & 27.004 \\
7 & Pharmacology & PHA & 2.087 \\
8 & Economics & ECO & 16.159 \\
9 & Management science and econometrics & MAN & 309 \\
10 & Law & LAW & 19.019 \\
11 & Social sciences & SOC & 20.520 \\
12 & Arts & ART & 1.487 \\
\end{tabular}

Table 20 provides the number of occupations and educations with non-zero totals, which are used in the analysis. 
Table 20. Number of occupations and university studies in data-sources

\begin{tabular}{lccc}
\hline source & \#occupations & $\begin{array}{c}\text { \#occupations after } \\
\text { correction }\end{array}$ & \#studies \\
\hline census 1947 & 49 & 57 & 10 \\
census 1960 & 38 & 48 & 11 \\
census 1971 & 66 & 76 & 11 \\
AKT 1979 & 42 & 53 & 12 \\
AKT 1981 & 55 & 66 & 12 \\
AKT 1983 & 55 & 66 & 12 \\
AKT 1985 & 58 & 69 & 12 \\
\hline
\end{tabular}

In section 5 some comparisons are made with figures concerning the unemployment ratio and the enrolment of the studies. The unemployment ratio's are taken from Dijkstra and Van Donk (1988), and the enrolment figures stem from C.B.S. (1973-1985).

4 Maps of the Dutch university studies 1947-1985

Figure 2 to 8 present the results of the similarity measurements of university studies in the years 1947-1985. Thick short lines indicate large similarities while educations with a low similarity are not connected with a line. Educations which have no close similarity with the rest of the studies are connected with a dashed line with the closest connection.

Below every map of the educational structure the matrix with exact similarities is added.

Legend for figure 2 to 8

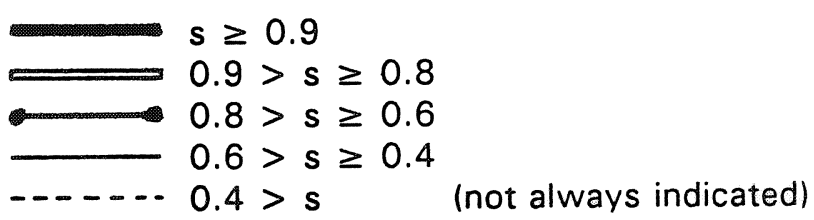


Figure 2. Map of the university labour market in 1947

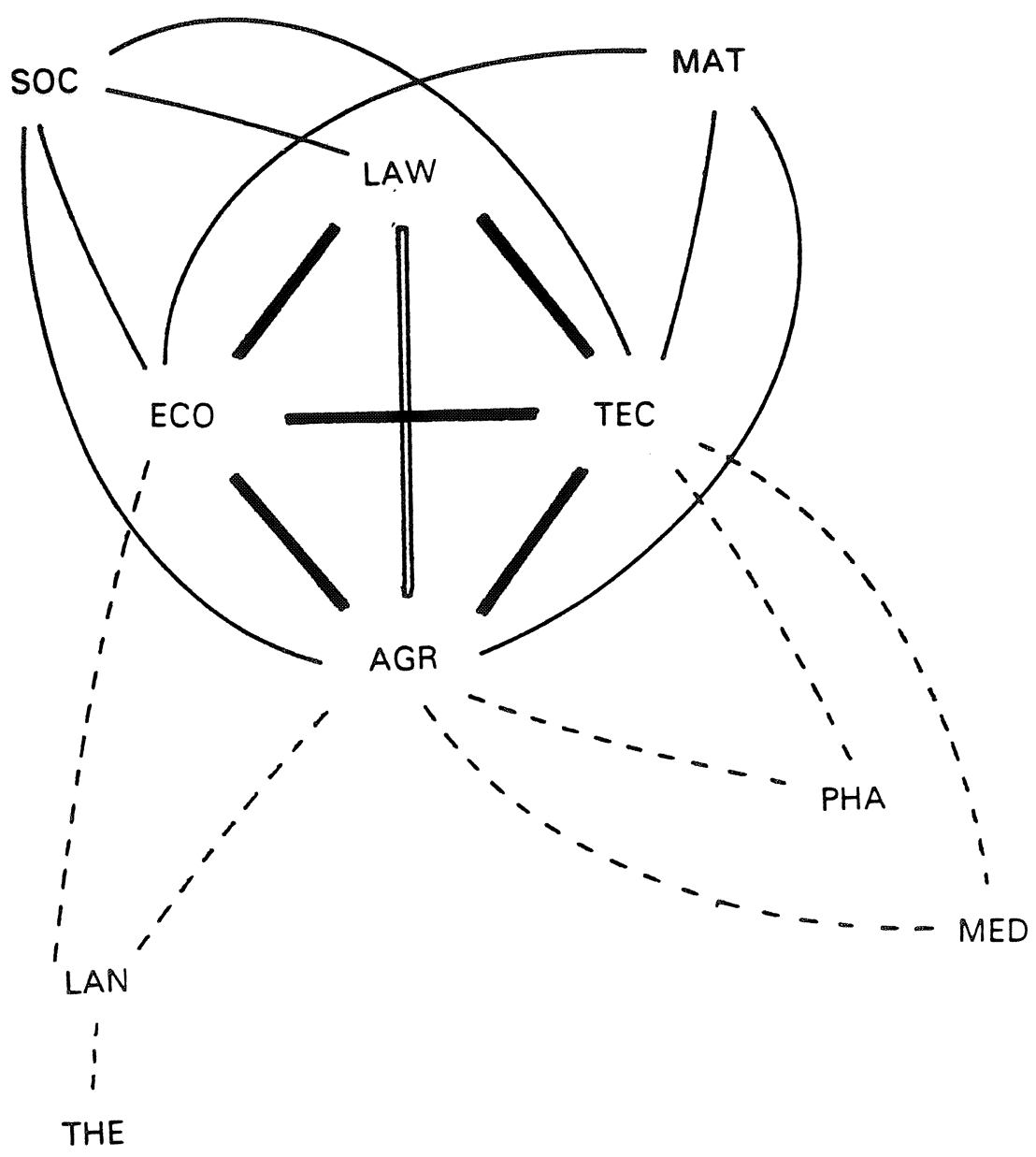

Table 21. Similarities in census 1947

\begin{tabular}{lllllllllllll}
\hline & LAN & THE & AGR & MAT & TEC & MED & PHA & ECO & MAN & LAW & SOC & ART \\
\hline LAN & 1.00 & 0.07 & 0.30 & 0.18 & 0.28 & 0.02 & 0.07 & 0.30 & 0.27 & 0.16 & \\
THE & 0.07 & 1.00 & 0.04 & 0.04 & 0.04 & 0.00 & 0.01 & 0.05 & 0.04 & 0.03 & \\
AGR & 0.30 & 0.04 & 1.00 & 0.51 & 0.95 & 0.08 & 0.23 & 0.95 & 0.91 & 0.43 \\
MAT & 0.18 & 0.04 & 0.51 & 1.00 & 0.48 & 0.05 & 0.18 & 0.47 & 0.43 & 0.23 \\
TEC & 0.28 & 0.04 & 0.95 & 0.48 & 1.00 & 0.08 & 0.23 & 0.92 & 0.84 & 0.41 \\
MED & 0.02 & 0.00 & 0.08 & 0.05 & 0.08 & 1.00 & 0.06 & 0.07 & 0.06 & 0.03 \\
PHA & 0.07 & 0.01 & 0.23 & 0.18 & 0.23 & 0.06 & 1.00 & 0.22 & 0.21 & 0.10 \\
ECO & 0.30 & 0.05 & 0.95 & 0.47 & 0.92 & 0.07 & 0.22 & 1.00 & 0.90 & 0.43 \\
MAN & & & & & & & & & & & \\
LAW & 0.27 & 0.04 & 0.91 & 0.43 & 0.84 & 0.06 & 0.21 & 0.90 & 1.00 & 0.41 \\
SOC & 0.16 & 0.03 & 0.43 & 0.23 & 0.41 & 0.03 & 0.10 & 0.43 & 0.41 & 1.00 \\
ART & & & & & & & & & & & &
\end{tabular}


Figure 3. Map of the university labour market in 1960

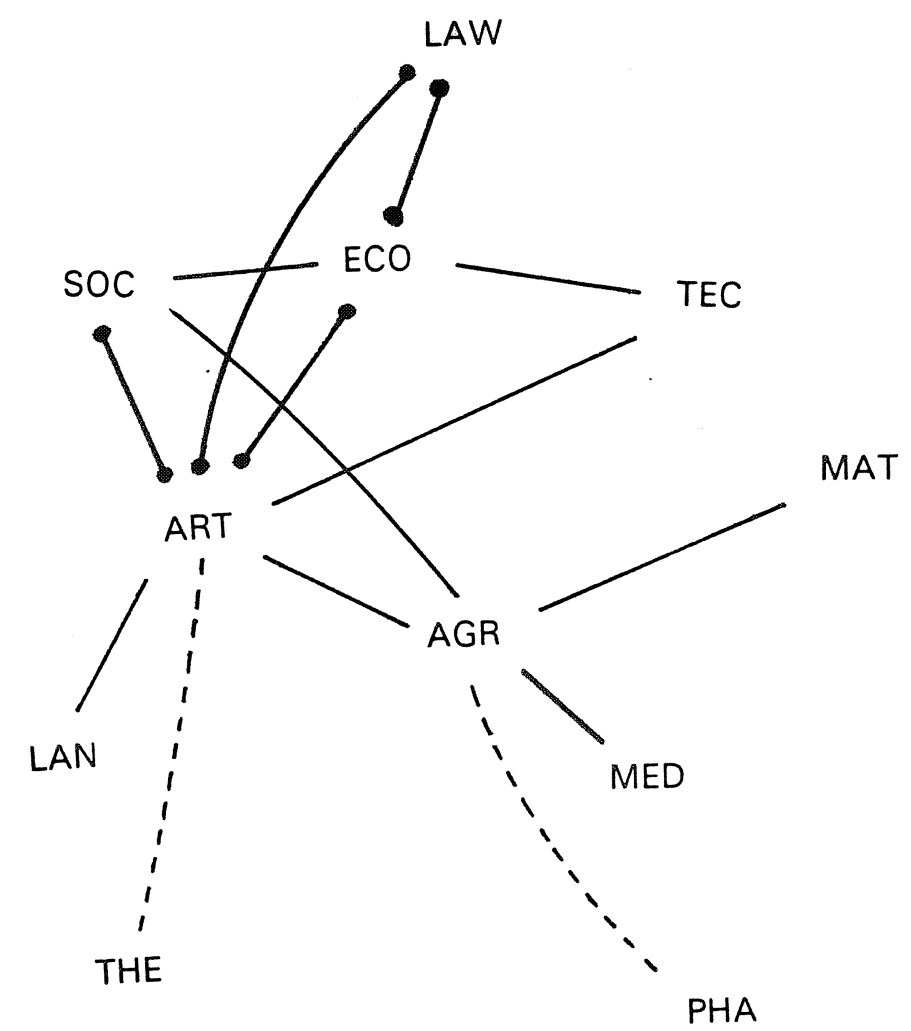

Table 22. Similarities in 1960

\begin{tabular}{lllllllllllll}
\hline & LAN & THE & AGR & MAT & TEC & MED & PHA & ECO & MAN & LAW & SOC & ART \\
\hline LAN & 1.00 & 0.06 & 0.11 & 0.08 & 0.09 & 0.03 & 0.04 & 0.16 & 0.19 & 0.26 & 0.52 \\
THE & 0.06 & 1.00 & 0.04 & 0.02 & 0.03 & 0.01 & 0.01 & 0.08 & 0.08 & 0.09 & 0.22 \\
AGR & 0.11 & 0.04 & 1.00 & 0.45 & 0.31 & 0.61 & 0.18 & 0.39 & 0.38 & 0.49 & 0.44 \\
MAT & 0.08 & 0.02 & 0.45 & 1.00 & 0.39 & 0.14 & 0.11 & 0.24 & 0.19 & 0.28 & 0.33 \\
TEC & 0.09 & 0.03 & 0.31 & 0.39 & 1.00 & 0.04 & 0.11 & 0.45 & 0.37 & 0.27 & 0.41 \\
MED & 0.03 & 0.01 & 0.61 & 0.14 & 0.04 & 1.00 & 0.09 & 0.06 & 0.06 & 0.22 & 0.14 \\
PHA & 0.04 & 0.01 & 0.18 & 0.11 & 0.11 & 0.09 & 1.00 & 0.11 & 0.11 & 0.12 & 0.13 \\
ECO & 0.16 & 0.08 & 0.39 & 0.24 & 0.45 & 0.06 & 0.11 & 1.00 & 0.69 & 0.41 & 0.62 \\
MAN & & & & & & & & & & & & \\
LAW & 0.19 & 0.08 & 0.38 & 0.19 & 0.37 & 0.06 & 0.11 & 0.69 & 1.00 & 0.43 & 0.71 \\
SOC & 0.26 & 0.09 & 0.49 & 0.28 & 0.27 & 0.22 & 0.12 & 0.41 & 0.43 & 1.00 & 0.67 \\
ART & 0.52 & 0.22 & 0.44 & 0.33 & 0.41 & 0.14 & 0.13 & 0.62 & 0.71 & 0.67 & 1.00 \\
\hline
\end{tabular}


Figure 4. Map of the university labour market in 1971

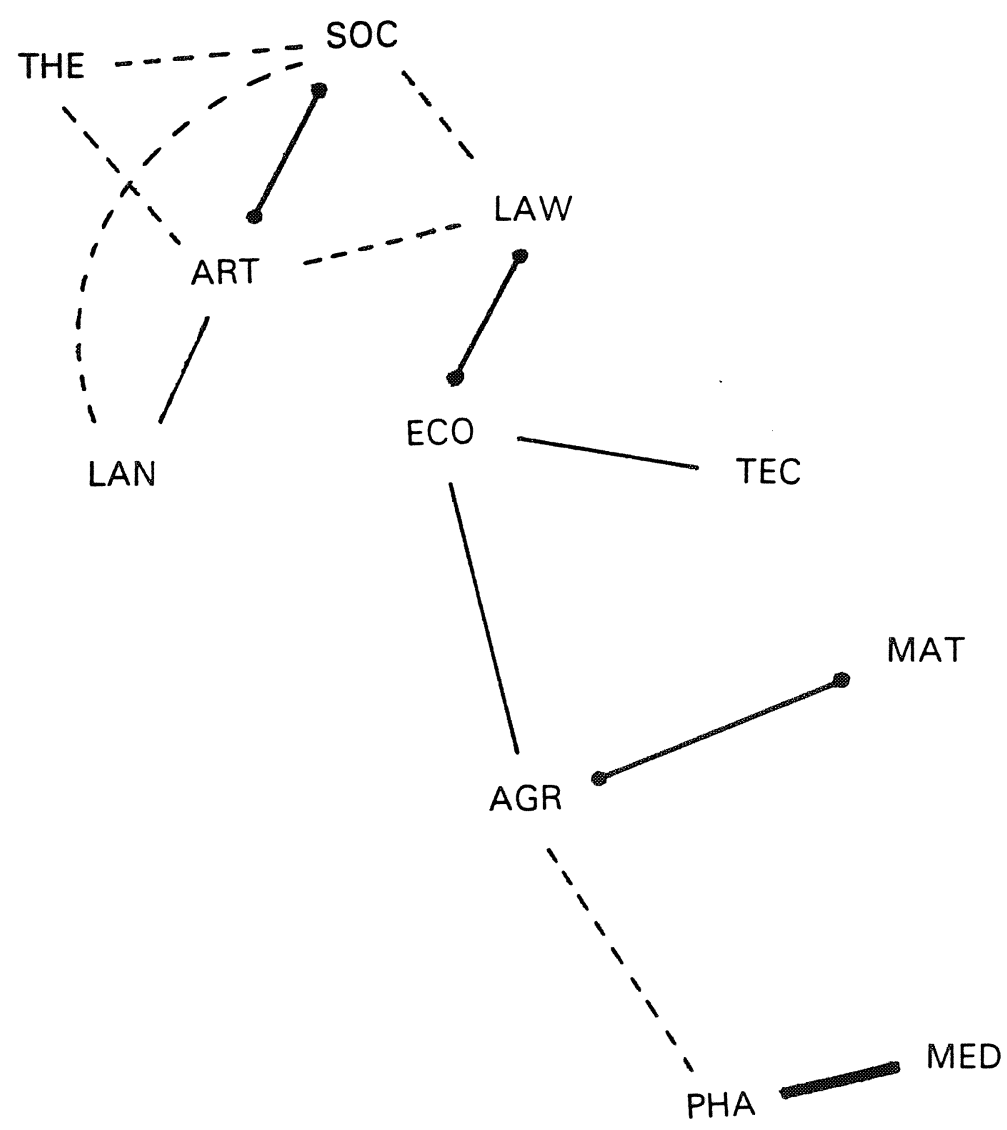

Table 23. Similarities in 1971

\begin{tabular}{lllllllllllll}
\hline & LAN & THE & AGR & MAT & TEC & MED & PHA & ECO & MAN & LAW & SOC & ART \\
\hline LAN & 1.00 & 0.16 & 0.12 & 0.07 & 0.10 & 0.02 & 0.02 & 0.13 & 0.16 & 0.39 & 0.40 \\
THE & 0.16 & 1.00 & 0.09 & 0.05 & 0.09 & 0.02 & 0.02 & 0.11 & 0.12 & 0.21 & 0.21 \\
AGR & 0.12 & 0.09 & 1.00 & 0.74 & 0.56 & 0.32 & 0.38 & 0.50 & 0.39 & 0.28 & 0.28 \\
MAT & 0.07 & 0.05 & 0.74 & 1.00 & 0.33 & 0.14 & 0.21 & 0.24 & 0.16 & 0.17 & 0.17 \\
TEC & 0.10 & 0.09 & 0.56 & 0.33 & 1.00 & 0.08 & 0.10 & 0.53 & 0.35 & 0.27 & 0.24 \\
MED & 0.02 & 0.02 & 0.32 & 0.14 & 0.08 & 1.00 & 0.99 & 0.09 & 0.06 & 0.05 & 0.06 \\
PHA & 0.02 & 0.02 & 0.38 & 0.21 & 0.10 & 0.99 & 1.00 & 0.11 & 0.08 & 0.06 & 0.07 \\
ECO & 0.13 & 0.11 & 0.50 & 0.24 & 0.53 & 0.09 & 0.11 & 1.00 & 0.60 & 0.33 & 0.32 \\
MAN & & & & & & & & & & & & \\
LAW & 0.16 & 0.12 & 0.39 & 0.16 & 0.35 & 0.06 & 0.08 & 0.60 & 1.00 & 0.37 & 0.39 \\
SOC & 0.39 & 0.21 & 0.28 & 0.17 & 0.27 & 0.05 & 0.06 & 0.33 & 0.37 & 1.00 & 0.75 \\
ART & 0.40 & 0.21 & 0.28 & 0.17 & 0.24 & 0.06 & 0.07 & 0.32 & & 0.39 & 0.75 & 1.00 \\
\hline
\end{tabular}


Figure 5. Map of the university labour market in 1979

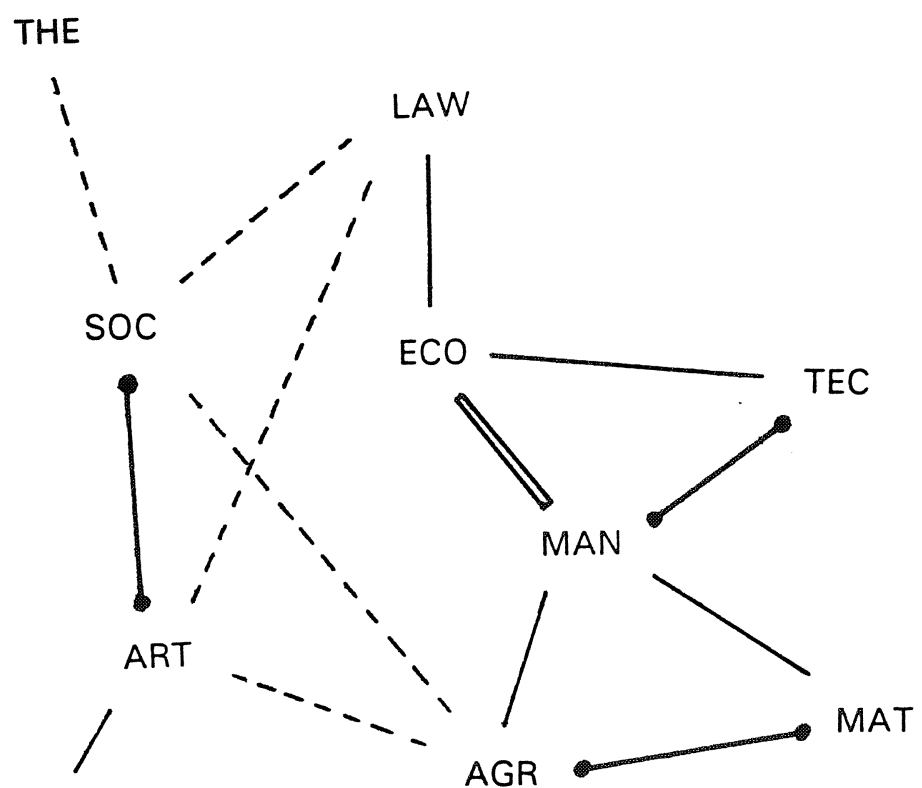

LAN

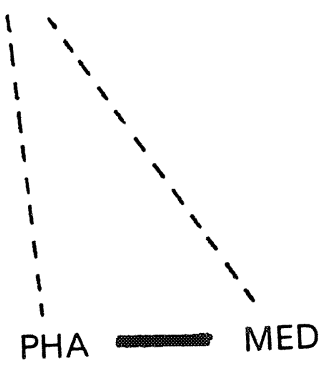

Table 24. Similarities in 1979

\begin{tabular}{lllllllllllll}
\hline & LAN & THE & AGR & MAT & TEC & MED & PHA & ECO & MAN & LAW & SOC & ART \\
\hline LAN & 1.00 & 0.10 & 0.15 & 0.12 & 0.13 & 0.04 & 0.06 & 0.14 & 0.10 & 0.17 & 0.36 & 0.43 \\
THE & 0.10 & 1.00 & 0.07 & 0.06 & 0.06 & 0.02 & 0.03 & 0.07 & 0.05 & 0.08 & 0.19 & 0.20 \\
AGR & 0.15 & 0.07 & 1.00 & 0.72 & 0.39 & 0.24 & 0.26 & 0.39 & 0.47 & 0.38 & 0.30 & 0.31 \\
MAT & 0.12 & 0.06 & 0.72 & 1.00 & 0.35 & 0.10 & 0.11 & 0.23 & 0.45 & 0.17 & 0.21 & 0.26 \\
TEC & 0.13 & 0.06 & 0.39 & 0.35 & 1.00 & 0.09 & 0.16 & 0.40 & 0.63 & 0.31 & 0.24 & 0.23 \\
MED & 0.04 & 0.02 & 0.24 & 0.10 & 0.09 & 1.00 & 1.00 & 0.09 & 0.05 & 0.07 & 0.12 & 0.11 \\
PHA & 0.06 & 0.03 & 0.26 & 0.11 & 0.16 & 1.00 & 1.00 & 0.16 & 0.13 & 0.11 & 0.16 & 0.14 \\
ECO & 0.14 & 0.07 & 0.39 & 0.23 & 0.40 & 0.09 & 0.16 & 1.00 & 0.88 & 0.46 & 0.27 & 0.25 \\
MAN & 0.10 & 0.05 & 0.47 & 0.45 & 0.63 & 0.05 & 0.13 & 0.88 & 1.00 & 0.29 & 0.22 & 0.22 \\
LAW & 0.17 & 0.08 & 0.38 & 0.17 & 0.31 & 0.07 & 0.11 & 0.46 & 0.29 & 1.00 & 0.30 & 0.31 \\
SOC & 0.36 & 0.19 & 0.30 & 0.21 & 0.24 & 0.12 & 0.16 & 0.27 & 0.22 & 0.30 & 1.00 & 0.75 \\
ART & 0.43 & 0.20 & 0.31 & 0.26 & 0.23 & 0.11 & 0.14 & 0.25 & 0.22 & 0.31 & 0.75 & 1.00 \\
\hline & & & & & & & & & & & &
\end{tabular}


Figure 6. Map of the university labour market in 1981
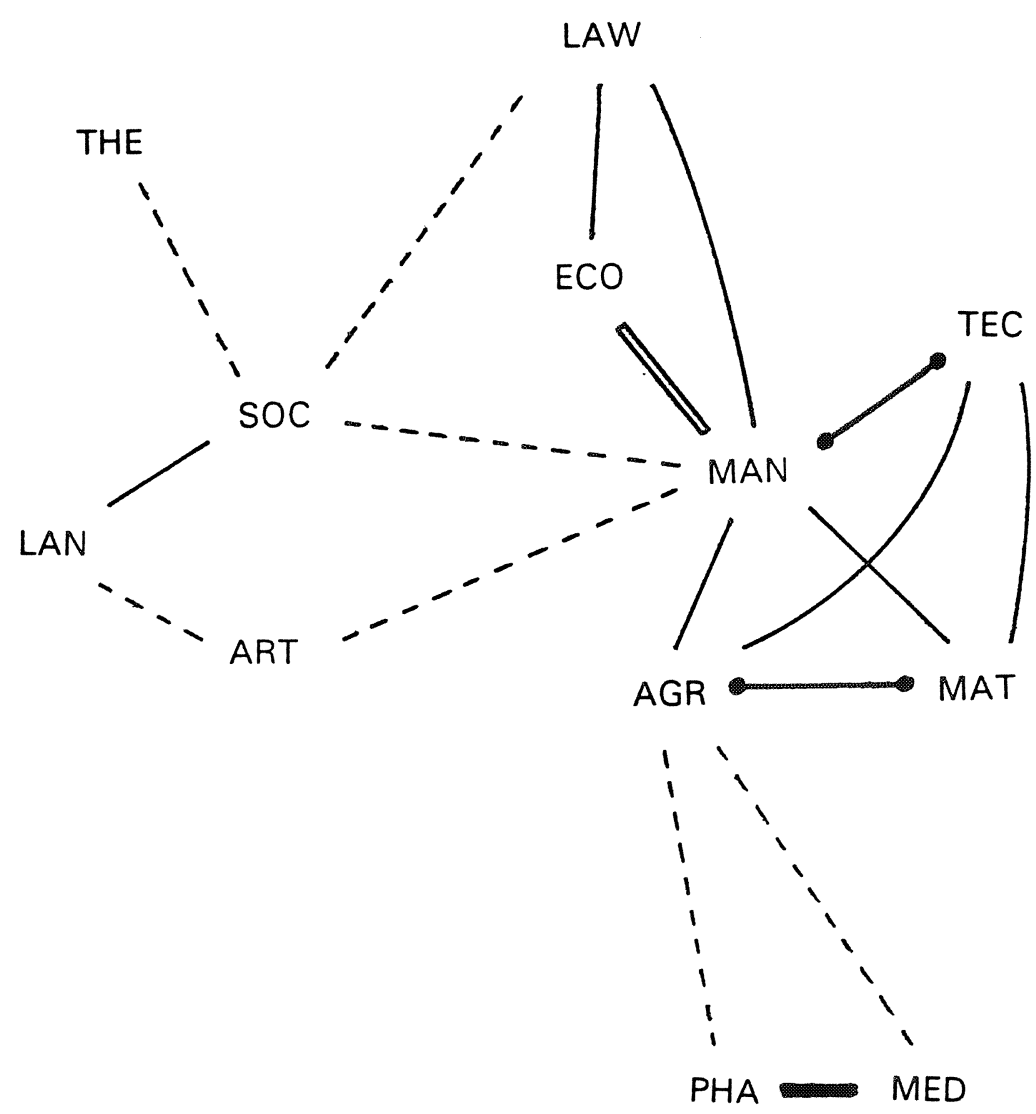

Table 25. Similarities in 1981

\begin{tabular}{llllllllllllll}
\hline & LAN & THE & AGR & MAT & TEC & MED & PHA & ECO & MAN & LAW & SOC & ART \\
\hline LAN & 1.00 & 0.10 & 0.13 & 0.10 & 0.13 & 0.04 & 0.07 & 0.14 & 0.19 & 0.20 & 0.48 & 0.36 \\
THE & 0.10 & 1.00 & 0.03 & 0.02 & 0.04 & 0.01 & 0.02 & 0.05 & 0.06 & 0.05 & 0.12 & 0.08 \\
AGR & 0.13 & 0.03 & 1.00 & 0.75 & 0.48 & 0.21 & 0.39 & 0.34 & 0.55 & 0.23 & 0.22 & 0.25 \\
MAT & 0.10 & 0.02 & 0.75 & 1.00 & 0.46 & 0.10 & 0.27 & 0.20 & 0.52 & 0.15 & 0.15 & 0.23 \\
TEC & 0.13 & 0.04 & 0.48 & 0.46 & 1.00 & 0.08 & 0.15 & 0.44 & 0.73 & 0.28 & 0.26 & 0.38 \\
MED & 0.04 & 0.01 & 0.21 & 0.10 & 0.08 & 1.00 & 0.97 & 0.08 & 0.09 & 0.07 & 0.08 & 0.05 \\
PHA & 0.07 & 0.02 & 0.39 & 0.27 & 0.15 & 0.97 & 1.00 & 0.13 & 0.19 & 0.12 & 0.13 & 0.11 \\
ECO & 0.14 & 0.05 & 0.34 & 0.20 & 0.44 & 0.08 & 0.13 & 1.00 & 0.86 & 0.45 & 0.27 & 0.24 \\
MAN & 0.19 & 0.06 & 0.55 & 0.52 & 0.73 & 0.09 & 0.19 & 0.86 & 1.00 & 0.41 & 0.38 & 0.38 \\
LAW & 0.20 & 0.05 & 0.23 & 0.15 & 0.28 & 0.07 & 0.12 & 0.45 & 0.41 & 1.00 & 0.32 & 0.29 \\
SOC & 0.48 & 0.12 & 0.22 & 0.15 & 0.26 & 0.08 & 0.13 & 0.27 & 0.38 & 0.32 & 1.00 & 0.61 \\
ART & 0.36 & 0.08 & 0.25 & 0.23 & 0.38 & 0.05 & 0.11 & 0.24 & 0.38 & 0.29 & 0.61 & 1.00 \\
\hline
\end{tabular}


Figure 7. Map of the university labour market in 1983

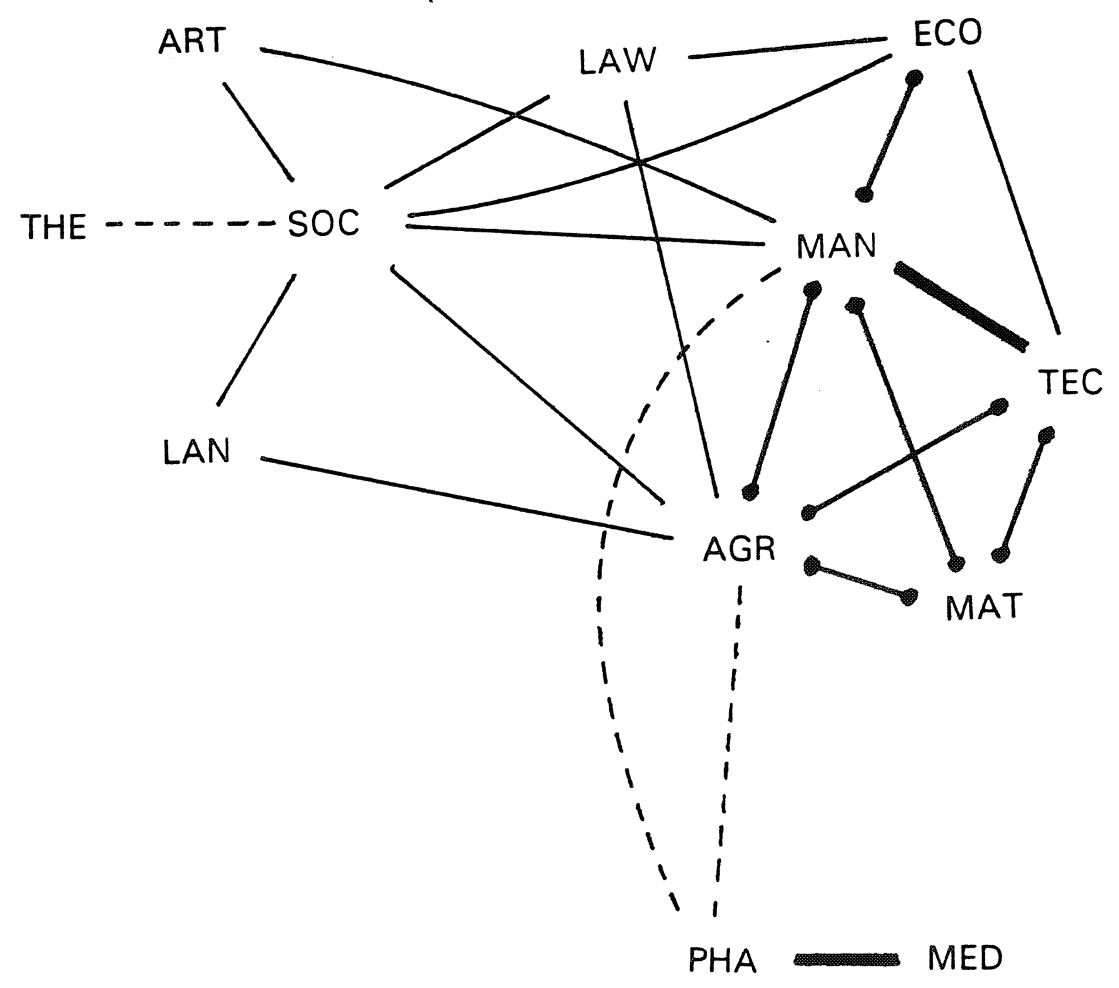

Table 26. Similarities in 1983

\begin{tabular}{lllllllllllll} 
& LAN & THE & AGR & MAT & TEC & MED & PHA & ECO & MAN & LAW & SOC & ART \\
\hline LAN & 1.00 & 0.12 & 0.25 & 0.15 & 0.15 & 0.05 & 0.09 & 0.18 & 0.25 & 0.21 & 0.42 & 0.34 \\
THE & 0.12 & 1.00 & 0.13 & 0.09 & 0.12 & 0.04 & 0.07 & 0.13 & 0.15 & 0.12 & 0.22 & 0.13 \\
AGR & 0.25 & 0.13 & 1.00 & 0.68 & 0.68 & 0.14 & 0.34 & 0.56 & 0.75 & 0.42 & 0.48 & 0.41 \\
MAT & 0.15 & 0.09 & 0.68 & 1.00 & 0.50 & 0.10 & 0.26 & 0.32 & 0.61 & 0.23 & 0.36 & 0.26 \\
TEC & 0.15 & 0.12 & 0.68 & 0.50 & 1.00 & 0.08 & 0.26 & 0.54 & 0.92 & 0.33 & 0.38 & 0.33 \\
MED & 0.05 & 0.04 & 0.14 & 0.10 & 0.08 & 1.00 & 0.96 & 0.09 & 0.14 & 0.08 & 0.13 & 0.10 \\
PHA & 0.09 & 0.07 & 0.34 & 0.26 & 0.26 & 0.96 & 1.00 & 0.29 & 0.35 & 0.22 & 0.24 & 0.19 \\
ECO & 0.18 & 0.13 & 0.56 & 0.32 & 0.54 & 0.09 & 0.29 & 1.00 & 0.74 & 0.53 & 0.40 & 0.35 \\
MAN & 0.25 & 0.15 & 0.75 & 0.61 & 0.92 & 0.14 & 0.35 & 0.74 & 1.00 & 0.47 & 0.55 & 0.43 \\
LAW & 0.21 & 0.12 & 0.42 & 0.23 & 0.33 & 0.08 & 0.22 & 0.53 & 0.47 & 1.00 & 0.44 & 0.32 \\
SOC & 0.42 & 0.22 & 0.48 & 0.36 & 0.38 & 0.13 & 0.24 & 0.40 & 0.55 & 0.44 & 1.00 & 0.58 \\
ART & 0.34 & 0.13 & 0.41 & 0.26 & 0.33 & 0.10 & 0.19 & 0.35 & 0.43 & 0.32 & 0.58 & 1.00 \\
\hline
\end{tabular}


Figure 8. Map of the university labour market in 1985

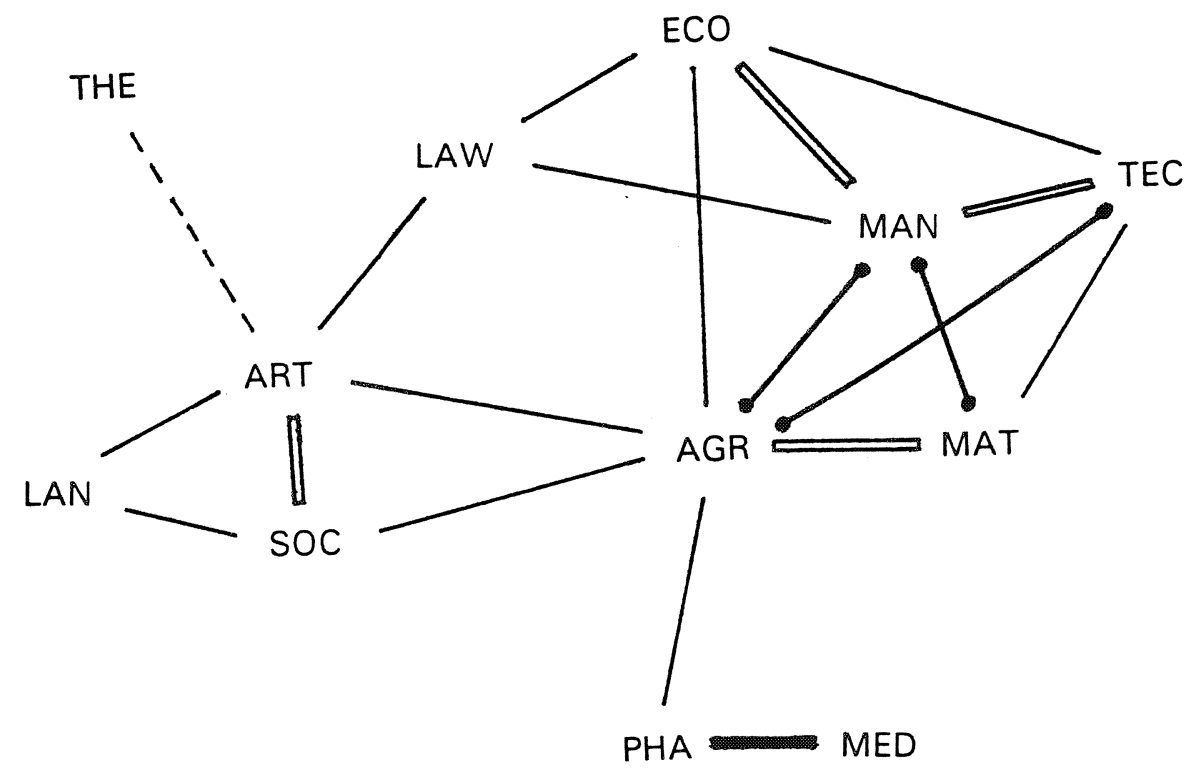

Table 27. Similarities in AKT 1985

\begin{tabular}{lllllllllllll}
\hline & LAN & THE & AGR & MAT & TEC & MED & PHA & ECO & MAN & LAW & SOC & ART \\
\hline LAN & 1.00 & 0.10 & 0.26 & 0.18 & 0.16 & 0.06 & 0.10 & 0.20 & 0.23 & 0.24 & 0.44 & 0.51 \\
THE & 0.10 & 1.00 & 0.10 & 0.08 & 0.09 & 0.02 & 0.05 & 0.11 & 0.13 & 0.10 & 0.14 & 0.17 \\
AGR & 0.26 & 0.10 & 1.00 & 0.80 & 0.64 & 0.24 & 0.47 & 0.55 & 0.70 & 0.39 & 0.46 & 0.44 \\
MAT & 0.18 & 0.08 & 0.80 & 1.00 & 0.54 & 0.13 & 0.39 & 0.36 & 0.54 & 0.22 & 0.31 & 0.29 \\
TEC & 0.16 & 0.09 & 0.64 & 0.54 & 1.00 & 0.07 & 0.21 & 0.54 & 0.88 & 0.27 & 0.27 & 0.25 \\
MED & 0.06 & 0.02 & 0.24 & 0.13 & 0.07 & 1.00 & 0.92 & 0.09 & 0.10 & 0.07 & 0.09 & 0.10 \\
PHA & 0.10 & 0.05 & 0.47 & 0.39 & 0.21 & 0.92 & 1.00 & 0.20 & 0.25 & 0.14 & 0.18 & 0.18 \\
ECO & 0.20 & 0.11 & 0.55 & 0.36 & 0.54 & 0.09 & 0.20 & 1.00 & 0.86 & 0.50 & 0.32 & 0.31 \\
MAN & 0.23 & 0.13 & 0.70 & 0.54 & 0.88 & 0.10 & 0.25 & 0.86 & 1.00 & 0.45 & 0.38 & 0.36 \\
LAW & 0.24 & 0.10 & 0.39 & 0.22 & 0.27 & 0.07 & 0.14 & 0.50 & 0.45 & 1.00 & 0.37 & 0.41 \\
SOC & 0.44 & 0.14 & 0.46 & 0.31 & 0.27 & 0.09 & 0.18 & 0.32 & 0.38 & 0.37 & 1.00 & 0.81 \\
ART & 0.51 & 0.17 & 0.44 & 0.29 & 0.25 & 0.10 & 0.18 & 0.31 & 0.36 & 0.41 & 0.81 & 1.00 \\
\hline
\end{tabular}


The structure of the university studies in 1947 was rather tight, indicating that many studies gave access to the same occupations. The core of this structure was formed by agricultural sciences, economics, law, and technology. Soon after 1947 a restructuring started, initially leading to less similarities between studies. In the eighties again a similar core is formed, with law no longer in a central position, but with mathematics and managerial sciences in the core. The position of managerial sciences is very remarkable. Soon after its introduction it got a central position, which even became more prominent throughout the years. Art also created a central position with its introduction in 1960, but disappeared to the periphery soon after. In the starting period of new educations, similarities with other studies might be rather large, due to the fact that the study did not create its own labour market segment at that moment. In the next section more evidence on the position of management science is provided.

In 1947, theology and the languages were slightly connected, but both very dissimilar from other studies. During the years these studies got slightly more similar to mainly art and social sciences. The closest connection of theology changed from languages to social sciences.

Medicines and pharmacology, also always have been very dissimilar to other studies. From 1971 these two studies got very similar, due to a reclassification in which physicians and pharmacists were treated as the same occupation. This is a strong example of the influence of classifications which are aggregated too much, since the evidence of the period before 1971 shows that these two studies do not have much similarity.

Table 28. Average similarity of the studies, measured by a hypothetical number of completely segmentated studies
year
number
corr. for size
corr. for similarity

$\begin{array}{llll}1947 & 10 & 5.19 & 2.84 \\ 1960 & 11 & 6.50 & 3.53 \\ 1971 & 11 & 6.42 & 3.04 \\ 1979 & 12 & 7.64 & 3.21 \\ 1981 & 12 & 7.59 & 3.19 \\ 1983 & 12 & 7.71 & 2.67 \\ 1985 & 12 & 7.68 & 2.81\end{array}$

Table 28 presents an indication for the degree of segmentation of the university labour market. For every year the average similarity between the studies has been calculated, weighted with the size of the studies at the market. The fourth column of table 28 gives the reciprocal of this average similarity, which can be interpreted as the number of equally sized studies with a completely own labour market segment, which would produce the same average similarity. E.g. the average similarity in 1971 is equal to the average similarity in the case in which there were three (3.04) equally large studies, each with a particular segment of the labour market at which no students from the other studies could get an occupation. 
The difference between the actual number of studies and the hypothetical number corrected for similarity is not only caused by similarities but also by unequal sizes. This effect is indicated in the third column. The table shows, according to what was shown by the maps, that after 1947 the similarities became smaller, but increased again in the eighties. 


\section{SPECIALISATION AND LABOUR MARKET BEHAVIOUR}

Using the similarity of occupations it is possible to calculate the Adjusted Gini-Hirschman index for the degree of specialisation. Table 29 gives the results for all the years.

Table 29. The adjusted Gini-Hirschman index

\begin{tabular}{llllllll}
\hline & 1947 & 1960 & 1971 & 1979 & 1981 & 1983 & 1985 \\
\hline LAN & 0.73 & 0.78 & 0.70 & 0.64 & 0.62 & 0.63 & 0.59 \\
THE & 0.94 & 0.92 & 0.74 & 0.75 & 0.82 & 0.74 & 0.74 \\
AGR & 0.75 & 0.53 & 0.44 & 0.45 & 0.45 & 0.39 & 0.36 \\
MAT & 0.60 & 0.66 & 0.70 & 0.69 & 0.70 & 0.57 & 0.55 \\
TEC & 0.76 & 0.76 & 0.80 & 0.76 & 0.72 & 0.74 & 0.78 \\
MED & 0.95 & 0.91 & 0.90 & 0.87 & 0.88 & 0.87 & 0.86 \\
PHA & 0.68 & 0.69 & 0.73 & 0.76 & 0.55 & 0.50 & 0.44 \\
ECO & 0.83 & 0.65 & 0.68 & 0.72 & 0.72 & 0.68 & 0.69 \\
MAN & & & & 0.41 & 0.40 & 0.49 & 0.53 \\
LAW & 0.85 & 0.83 & 0.72 & 0.70 & 0.71 & 0.68 & 0.68 \\
SOC & 0.55 & 0.48 & 0.74 & 0.75 & 0.77 & 0.73 & 0.79 \\
ART & & 0.49 & 0.47 & 0.45 & 0.45 & 0.50 & 0.53 \\
\hline
\end{tabular}

For most studies which existed already in 1947 the degree of specialisation fell. The only two exceptions are technology, with only a very small increase in specialisation and social sciences with a rather large increase. The two studies introduced after 1947, art and managerial sciences, also had a rise in specialisation.

In 1947 and 1960 some studies were extremely specialised. Law and theology lost much of this specialisation. Only medicines remained a very job-specific study, although not as extreme as in 1947.

The adjusted Gini-Hirschman index might differ largely from the usual Gini-Hirschman index. Table 30 gives both indexes for 1979. All indexes increase due to the adjustment, since the similarities can only rise in the adjusted Gini-Hirschman index. The extent of this increase, however, differs widely. For economics this is most extreme. Measured with the usual GiniHirschman index economics is the most general study, while measured with the adjusted GiniHirschman index it is the seventh general study. 
Table 30. A comparison of the adjusted and the usual Gini-Hirschman index in 1979

\begin{tabular}{lll}
\hline & GH & AGH \\
\hline LAN & 0.52 & 0.64 \\
THE & 0.52 & 0.75 \\
AGR & 0.25 & 0.45 \\
MAT & 0.21 & 0.69 \\
TEC & 0.38 & 0.76 \\
MED & 0.76 & 0.87 \\
PHA & 0.73 & 0.77 \\
ECO & 0.16 & 0.72 \\
MAN & 0.30 & 0.41 \\
LAW & 0.30 & 0.70 \\
SOC & 0.36 & 0.75 \\
ART & 0.27 & 0.45 \\
\hline
\end{tabular}

Table 31. The adjusted Gini-Hirschman index with intermediate measurements, based on the distribution in the new situation, and similarities in the old situation

\begin{tabular}{llllllll}
\hline & 1979 & $(79 / 81)$ & 1981 & $(81 / 83)$ & 1983 & $(83 / 85)$ & 1985 \\
\hline LAN & 0.64 & 0.60 & 0.62 & 0.63 & 0.63 & 0.57 & 0.59 \\
THE & 0.75 & 0.83 & 0.82 & 0.72 & 0.74 & 0.74 & 0.74 \\
AGR & 0.45 & 0.39 & 0.45 & 0.35 & 0.39 & 0.37 & 0.36 \\
MAT & 0.69 & 0.71 & 0.70 & 0.54 & 0.57 & 0.56 & 0.55 \\
TEC & 0.76 & 0.66 & 0.72 & 0.67 & 0.74 & 0.76 & 0.78 \\
MED & 0.87 & 0.89 & 0.88 & 0.87 & 0.87 & 0.83 & 0.86 \\
PHA & 0.77 & 0.56 & 0.55 & 0.51 & 0.50 & 0.40 & 0.44 \\
ECO & 0.72 & 0.69 & 0.72 & 0.67 & 0.68 & 0.69 & 0.69 \\
MAN & 0.41 & 0.40 & 0.41 & 0.43 & 0.49 & 0.52 & 0.53 \\
LAW & 0.70 & 0.68 & 0.71 & 0.67 & 0.68 & 0.67 & 0.68 \\
SOC & 0.75 & 0.74 & 0.77 & 0.69 & 0.73 & 0.76 & 0.79 \\
ART & 0.45 & 0.43 & 0.45 & 0.41 & 0.50 & 0.46 & 0.53 \\
\hline
\end{tabular}

The difference in the Gini-Hirschman index between two years is caused by two factors. Firstly, the distribution of people with a certain educational background over the occupations changes. Secondly, the similarities between the occupation might change. In table 31 an adjusted GiniHirschman index is presented, based on the distribution in the new situation, and similarities in the old situation. 
Mostly, the change of the Gini-Hirschman index between two years measured with the old similarities, is larger than the change calculated with the new similarity. If people with a certain educational background get many new occupations in an specific occupation it is very likely that also people from other occupations are attracted to this growing occupation, thereby increasing the similarity of this occupation with other occupations.

There are only two exceptions to this rule, the decline in specialisation of pharmacology from 1979 till 1983, and the rise in specialisation of managerial sciences from 1981 till 1985. It seems to be the case that managerial sciences is specialising in occupations which are becoming more specific itself. Managerial sciences is creating its own labour market segment by specialising and displacement of other studies, while pharmacology got more flexible, not due to some demand side labour market opportunities, but because of some study-specific changes.

In section 2 the remark is made, that if the labour market is cleared by wages and these wages equal the marginal productivity of labour, people with a more specialised education will earn more given the occupation, but their wages will in general vary more than people with more flexible education. In case of unemployment, and wage-rigidities, however, this relationship might reverse. In the situation of a shortage employers will first employ the more specialised workers. Studies with a larger labour market flexibility will therefore be more sensitive for unemployment. Table 32 presents some indicators to measure the relation between specialisation and labour market performance. Firstly, a regression has been performed which explains changes in the rate of unemployment from 1979 to 1987 of a specific study by the average change in the unemployment rate:

(9) $\Delta U_{i}=\alpha_{i} \Delta \bar{U}+\epsilon_{i t}$

$\alpha_{i}$ indicates the sensitivity of study $i$ to general unemployment spells. If this parameter is larger than 1, as for example in languages, social sciences and art, a rise in the average rate of unemployment will lead to a more than proportional raise in this study.

The unemployment variation is the variance of the error term of this regression corrected for the size of unemployment:

(10) $U V_{i}=\operatorname{VAR}\left\{\frac{\varepsilon_{i t}}{U_{i t}}\right\}$

The idea behind this indicator is that specialised studies, although they might have a low sensitivity to average unemployment spells, have a high risk of idiosyncratic variation in unemployment.

Finally, the fourth column of table 32 gives the variation in enrolment in the period 1973-1985, corrected for changes in the total enrolment. Similar to the unemployment variation, first a 
regression of enrolment in study $i$ on total enrolment has been performed, and based on its residuals the enrolment variation has been calculated:

$$
E V_{i}=\operatorname{VAR}\left\{\frac{\epsilon_{i t}}{\text { Enrol }_{i t}}\right\}
$$

If students partially base their enrolment decisions on the labour market situation, studies with large fluctuations in labour market perspectives will also have large fluctuations in enrolment.

Table 32. Relation between education-specific unemployment and average unemployment, unemployment variation and enrolment variation

sensitivity for

unemployment $\left(\alpha_{i}\right) \quad$ unemployment variation enrolment variation

$\begin{array}{llll}\text { LAN } & 1.86 & 0.0045 & 0.0073 \\ \text { THE } & 0.60 & 0.0057 & 0.05108 \\ \text { AGR } & 1.15 & 0.0045 & 0.02239 \\ \text { MAT } & 1.11 & 0.0035 & 0.00390 \\ \text { TEC } & 0.66 & 0.0192 & 0.00509 \\ \text { MED } & 0.76 & 0.0205 & 0.01323 \\ \text { PHA } & 0.77 & 0.0259 & 0.06690 \\ \text { ECO } & 0.52 & 0.0273 & 0.01059 \\ \text { MAN } & - & - & 0.07607 \\ \text { LAW } & 0.76 & 0.0081 & 0.01260 \\ \text { SOC } & 1.51 & 0.0019 & 0.00786 \\ \text { ART } & 3.01 & 0.0043 & 0.02868\end{array}$

Based on these unemployment indicators, the relation between degree of specialisation and unemployment situation is analysed. The unemployment figures are not available for managerial sciences. Therefore this study is left out of this analysis. Since the similarities between studies were relatively low in 1979 the regression is based on the adjusted Gini-Hirschman index of this year. Table 33 gives the results of the regression. It shows a clear relation between the flexibility of a study and both its sensitivity to unemployment and high variation in unemployment rates. Studies with a more general curriculum are more sensitive to unemployment spells than specialised studies. These specialised studies do have, on the other hand, much more individual variation in unemployment. Due to the specialisation they have much more specific labour market risk. 
Table 33. Least squares estimation of the adjusted Gini-Hirschman index in 1979

Dependent variable: $A G H_{i}$

\begin{tabular}{lllll}
\hline & constant & sensitivity & variation & $R^{2}$ \\
\hline 1 & 0.77 & -0.097 & 2.84 & 0.49 \\
& $(7.69)$ & $(1.83)$ & $(0.71)$ & \\
2 & 0.82 & -0.12 & & 0.45 \\
& $(14.14)$ & $(2.73)$ & & \\
3 & 0.61 & & 6.90 & 0.27 \\
& $(10.95)$ & & $(1.83)$ & \\
\hline
\end{tabular}

Thus, both general and specialised studies have their specific risk regarding unemployment. While for specialised studies there is the risk that for its specific occupations the market is bad at the moment they enter the labour market, the general studies face the risk of general unemployment spells of which they will bear most part of the burden.

Table 34. Least squares estimation of the variation in enrolment

Dependent variable: $E V_{i}$.

\begin{tabular}{llll}
\hline & constant & Adj. Gini-Hirschman & $R^{2}$ \\
\hline 1 & 0.064 & -0.059 & 0.12 \\
& $(1.85)$ & $(1.14)$ & \\
2 & 0.042 & -0.043 & 0.54 \\
& $(3.99)$ & $(2.85)$ & \\
\hline
\end{tabular}

The optimum between specialised and general studies therefore depends on the circumstances. It will however, in general, be difficult to foresee an increase in unemployment in a specific labour market segment, while average unemployment is better predictable, because of the long duration of unemployment spells. It might be expected, therefore, that general studies will adjust more to the circumstances than specialised. This relation is estimated in table 34 . Estimation 1 indicates this relation, but with a very low $R^{2}$ and a low t-ratio. The bad fit is mainly due to three outliers, managerial science, theology and agricultural sciences, with all an extremely high variation in inflow. This variation is most likely caused by other changes. For managerial science, this is e.g. the introduction and rapid growth in the beginning. In estimation 2 these three studies with a variation above 0.05 have been omitted. The parameter estimates are comparable to estimation 1 but now, the t-ratio and the $R^{2}$ increased largely. 


\section{CONCLUDING REMARKS}

The aim of this paper has been to measure the structure of the Dutch university labour market. Based on the Gini-Hirschman index and the cosine similarity function both the degree of specialisation of studies and their mutual position have been measured. Section 4 and 5 present the main results of these calculations. Three remarks with respect to these calculations have to be made.

Firstly, as remarked also by De Grip and Heijke (1989), it is not the case that every university study has its own labour market segment. In fact there exists a rather complex structure in which people with different education are in the same occupational class.

Secondly, the relation between education and occupation is far from constant through time. The demand for labour changes through time and therefore education also changes. New educations create their own segment at the labour market replacing other studies partially, while existing studies shift their emphasis.

Finally, to be able to measure the structure of the labour market it is important to have detailed, high quality data on the labour force. Furthermore it is important that these data are based on useful classifications. Classifications should be detailed enough to separate completely different occupations and definitions of occupations should only depend on the kind of activities and not on the educational background of the worker. This is a necessary condition to be able to measure the similarities between studies. Of course, data should also be detailed enough. Due to its size, together with a high lower bound to avoid privacy problems, it is difficult to use the EBB (successor of the AKT) for similarity measurement. At lower educational level some new sources of data like RUBS and HBO-monitor ${ }^{2}$ provide, however, interesting possibilities to measure the educational structure of the labour market at very detailed level.

2. See ROA (1992). 


\section{REFERENCES}

C.B.S. (1973-1985), 'Statistiek van het wetenschappelijk onderwijs 1985' and its predecessors, Voorburg.

De Grip, A., L.F.M. Groot and J.A.M. Heijke (1991), 'Defining Occupational Groupings by Educational Structure'. Environment and Planning A 23, pp. 59-85.

De Grip, A. and J.A.M. Heijke (1989), 'Het flexibiliteitspotentieel van universitaire studierichtingen'. Tijdschrift voor Arbeidsvraagstukken 5, pp. 69-81.

Dekker, R.J.P., A. de Grip, Th. B.J. Beekman, P.J.E. van de Loo, M.H. Wieling and E.J.T.A. Willems (1990), Rapportage I-See!. Maastricht, ROA-R-1990/6.

Dijkstra, F.Y. and J.A.C. van de Donk (1988), De arbeidsmarkt van hoger opgeleiden per opleidingscategorie van 1978 to 2000. HW/T-notitie, Ministerie van Onderwijs en Wetenschappen, Zoetermeer.

Dothan, U. and J. Williams (1981), 'Education as an Option'. Journal of Business 54, pp. 117139.

Lorr, M. (1983), Cluster Analysis for Social Scientists. San Fransisco.

ROA (1992), Annual Report. Maastricht.

Sheldon, G. (1985), Die berufliche und geographische Flexibilität. dissertation, Institut für Arbeidsmarkt- und Berufsforschung der Bundesanstalt für Arbeit, Nürnberg.

Teulings, C. (1988), 'De grenzen van beroepsdeelmarkten'. Tijdschrift voor Arbeidsvraagstukken, 4, pp. 46-61.

Warnken, J. (1986), 'Zur Entwicklung der "Internen" Anpassungsfähigkeit der Berufe bis zum Jahre 2000. Projektionen unter den Annahmen der Wachstumzenarien der Prognos-Studie'. Mitteilungen aus der Arbeidsmarkt- und Berufsforschung 1, pp. 119-133. 


\section{APPENDIX}

Below, a program is printed which calculates the similarities, and (adjusted) Gini-Hirschman index. The program is written in Turbo-Pascal. As input an input file is needed with the extension '.dat'. This input file should consist of, firstly, two numbers indicating the number of studies and the number of occupations, and secondly, a matrix with numbers of workers with an education in an occupation. Different occupation should correspond with different columns and different educations with different rows.

The program generates a file with a name equal to the input file except of the extension '.out'.

PROGRAM map;

\section{CONST}

educ_max $=12$;

occ_max $=100$;

\section{VAR}

$\mathrm{i}, \mathrm{ii}, \mathrm{j}$, jj, stage,

educ_number, occ_number: INTEGER;

a: ARRAY[1..educ_max,1..educ_max] OF INTEGER;

gh_educ, sim_educ: ARRAY[1..educ_max,1..educ_max] OF REAL;

gh_occ, sim_occ: ARRAY[1..occ_max,1..occ_max] OF REAL;

educ_total: ARRAY[1..educ_max] OF INTEGER;

occ_total: ARRAY[1..occ_max] OF INTEGER;

input_data, output_data: TEXT;

input: STRING [8];

BEGIN

input : = 'matrix';

ASSIGN(input_data, ' $c: l^{\prime}+$ input + '.dat');

ASSIGN(output_data, 'c:l' + input +' .out');

RESET(input_data);

REWRITE(output_data);

READ(input_data, educ_number, occ_number);

IF ((educ_number > educ_max) OR (occ_number > occ_max)) THEN

BEGIN

WRITELN(output_data, 'Input matrix is too large');

WRITELN(output_data, 'Maximal size:');

WRITELN(output_data, educ_max:4, ' educations and');

WRITELN(output_data, occ_max:4, ' occupations.')

END 


\section{ELSE}

\section{BEGIN}

WRITELN(output_data, 'Input matrix');

WRITELN(output_data);

FOR $\mathrm{i}:=1$ TO educ_number DO

BEGIN

FOR $\mathrm{j}:=1$ TO occ_number DO

BEGIN

READ(input_data, a[i,j]);

WRITE(output_data, a[i,j]:8)

END;

WRITELN(output_data)

END;

WRITELN(output_data);

WRITELN(output_data);

WRITELN(output_data, 'Education totals');

WRITELN(output_data);

FOR $i:=1$ TO educ_number DO

BEGIN

educ_total[i] : $=0$;

FOR $\mathrm{j}:=1$ TO occ_number DO

educ_total[i] $:=$ educ_total $[i]+a[i, j]$;

WRITELN(output_data, i:5, educ_total[i]:8)

END;

WRITELN(output_data);

WRITELN(output_data);

WRITELN(output_data, 'Occupation totals');

WRITELN(output_data);

FOR $\mathrm{j}:=1$ TO occ_number DO

BEGIN

occ total[j] : = 0;

FOR $\mathrm{i}:=1$ TO educ_number DO

occ_total[j] : = occ_total[j] $+a[i, j]$;

WRITELN(output_data, j:5, occ_total[j]:8)

END;

FOR $\mathrm{i}:=1$ TO educ_number DO

FOR ii : = 1 TO educ_number DO

IF $\mathrm{i}=\mathrm{ii}$ THEN sim_educ $[\mathrm{i}, \mathrm{ii}]:=1$ ELSE sim_educ $[\mathrm{i}, \mathrm{ii}]:=0$; 


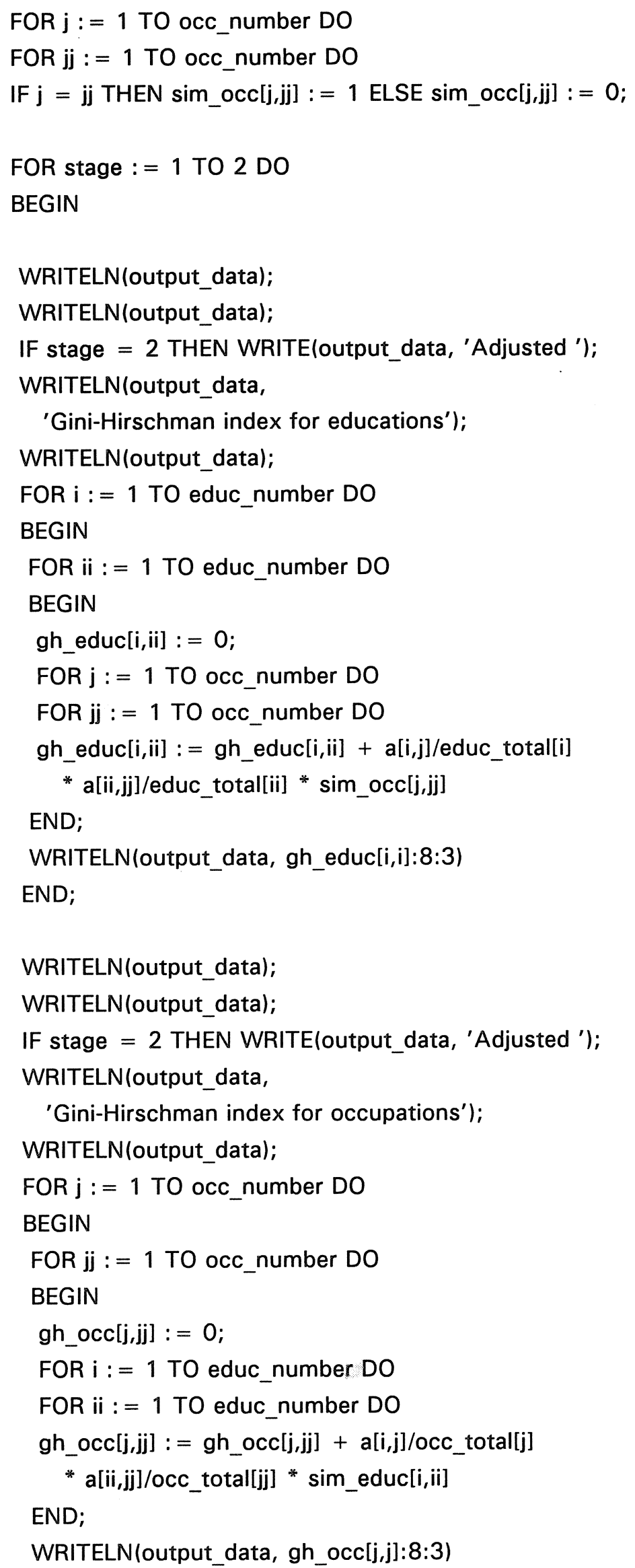

